\title{
Analysis of Energetics and Economics of Sub-ambient Hybrid Post-Combustion CO2 Capture
}

\author{
Stephen DeWitt ${ }^{1}$, Rohan Awati ${ }^{1}$, Héctor Rubiera Landa ${ }^{2}$, Jongwoo Park ${ }^{1}$, Yoshiaki \\ Kawajiri $^{2}$, David Sholl ${ }^{1}$, Matthew Realff ${ }^{2}$, and Ryan Lively ${ }^{1}$ \\ ${ }^{1}$ Georgia Tech \\ ${ }^{2}$ Georgia Institute of Technology
}

January 3, 2021

\begin{abstract}
Adsorption of $\mathrm{CO} 2$ from post-combustion flue gas is one of the leading candidates for globally-impactful carbon capture systems. This work highlights opportunities and limitations of sub-ambient CO2 capture processes utilizing a multi-stage separation process. A hybrid process design using a combination of pressure-driven separation of $\mathrm{CO} 2$ from flue gas followed by $\mathrm{CO} 2-$ rich product liquefaction to produce high purity ( $>99 \%) \mathrm{CO} 2$ at pipeline conditions is considered. The economic viability of applying pressure swing adsorption (PSA) processes using fiber sorbent contactors with internal heat management were found to be most influenced by the productivity of the adsorption system. Three exemplar fiber sorbents (MIL-101(Cr), UiO-66, and zeolite 13X) were considered for application in the sub-ambient process of PSA unit. MIL-101(Cr) and UiO-66 fiber composites were estimated to have costs of capture as low as $\$ 61 /$ tonne $\mathrm{CO} 2$.
\end{abstract}

\section{Analysis of Energetics and Economics of Sub-ambient Hybrid Post-Combustion $\mathrm{CO}_{2}$ Capture}

Stephen J. A. DeWitt, Rohan Awati, Héctor Octavio Rubiera Landa, Jongwoo Park, Yoshiaki Kawajiri ${ }^{+}$, David S. Sholl, Matthew Realff, Ryan P Lively*

School of Chemical \& Biomolecular Engineering, Georgia Institute of Technology, Atlanta, GA 30332, USA

\begin{abstract}
:
Adsorption of $\mathrm{CO}_{2}$ from post-combustion flue gas is one of the leading candidates for globally-impactful carbon capture systems. This work highlights opportunities and limitations of sub-ambient $\mathrm{CO}_{2}$ capture processes utilizing a multi-stage separation process. A hybrid process design using a combination of pressuredriven separation of $\mathrm{CO}_{2}$ from flue gas followed by $\mathrm{CO}_{2}$-rich product liquefaction to produce high purity $(>99 \%) \mathrm{CO}_{2}$ at pipeline conditions is considered. The economic viability of applying pressure swing adsorption (PSA) processes using fiber sorbent contactors with internal heat management were found to be most influenced by the productivity of the adsorption system. Three exemplar fiber sorbents (MIL-101(Cr), UiO66 , and zeolite 13X) were considered for application in the sub-ambient process of PSA unit. MIL-101(Cr) and UiO-66 fiber composites were estimated to have costs of capture as low as $\$ 61 /$ tonne $\mathrm{CO}_{2}$.
\end{abstract}

Topical Headline: Separations, Materials, Devices and Processes

Keywords: $\mathrm{CO}_{2}$ Capture, Pressure Swing Adsorption, Sub-ambient Process, Fiber Sorbents, Heat Management 


\section{Introduction}

The rising concentration of atmospheric $\mathrm{CO}_{2}$ serves as a contributor to changing climate patterns across the globe. ${ }^{1}$ Indeed, since the industrial revolution, the concentration of $\mathrm{CO}_{2}$ in the atmosphere has nearly doubled as a result of burning energy-dense carbon sources like coal, oil, and gasoline. ${ }^{2}$ A key challenge in the coming years will be to find ways to curb the release of $\mathrm{CO}_{2}$ to the atmosphere. ${ }^{3}$ If it is economically viable, capture of $\mathrm{CO}_{2}$ from point sources like coal-fired power plants has potential to be a crucial part of the global transition to a carbon-constrained world. ${ }^{4}$ Materials advances in sorbents ${ }^{5-9}$ solvents, ${ }^{10-13}$ and membranes ${ }^{14-17}$ over the past two decades have been a chief focus of research on $\mathrm{CO}_{2}$ capture from coal flue gas. Moreover, new process designs and intensification techniques have been considered to reduce the inherent energy consumption associated with these processes. Post-combustion $\mathrm{CO}_{2}$ is a challenging separation as the separation system must contend with high volumetric flowrates of $\mathrm{CO}_{2}$-dilute flue gases that are saturated with water and laden with acid gases. ${ }^{18,19}$ Specifically, the flue gas derived from coal-fired power plants contains water, oxygen, and trace acid gases $\left(\mathrm{SO}_{\mathrm{x}}\right.$ and $\left.\mathrm{NO}_{\mathrm{x}}\right)$, all of which must be considered when engineering an effective $\mathrm{CO}_{2}$ capture system. ${ }^{20,21}$ The challenges of both scale and composition must be accounted for when considering different methods of separation.

These issues with scale lead to the commonly held opinion that for $\mathrm{CO}_{2}$ capture processes from dilute point sources any form of pretreatment, whether adjusting temperature, pressure, or removal of additional contaminants or water, ${ }^{22}$ will result in impractical economics. ${ }^{23,24}$ In this paper we will reexamine this assumption. Inspired by the work of Hasse et al. and others, who proposed a sub-ambient membrane process that required considerable flue gas pretreatment, the work discussed here focuses on the design of pretreatment systems for any separation process that relies on pressure driving forces (in particular, membranes and pressure swing adsorption). ${ }^{25-29}$ The critical consideration in any sub-ambient pressuredriven $\mathrm{CO}_{2}$ capture process is the removal of heat from the feed. External refrigeration cycles have been shown to be extremely expensive, ${ }^{30}$ so the main portion of what makes the process proposed by Hasse et al. economically viable is their ability to run the sub-ambient process without the need for any external cooling utility.

It is helpful to simplify the process we considered into two distinct sub-processes: one that provides cooling through compression and expansion of flue gas components, and a second that produces the purified $\mathrm{CO}_{2}$ to pipeline specifications (see Figure 1). The expansion of the $\mathrm{N}_{2}$ product provides cooling to both the feed after compression and the $\mathrm{CO}_{2}$ product stream, as shown in Figure 1. The expansion of the $\mathrm{N}_{2}$ product is carried out on a stream that is already moderately cold through heat integration and removes the heat of compression. This also allows for the cooling of the $\mathrm{CO}_{2}$ product prior to its liquefaction.

In this work, we consider the economic viability of sub-ambient pressure-driven separation of $\mathrm{CO}_{2}$ from coalfired flue gas. Upstream pretreatment systems are discussed in detail, including those used for removal of water from the flue gas, compression of the flue gas, and cooling to the target conditions as well as downstream systems used for energy recovery from waste streams, product liquefaction, and pipeline delivery. In addition, sensitivity of the process energetics and economics to variation in these process variables are discussed. The process framework's viability is considered for the case of thermally-modulated fiber sorbents ${ }^{31-33}$ for application in a pressure swing adsorption (PSA) process, mainly focusing on how separation performance (productivity and purity) impacts the economics of post-combustion $\mathrm{CO}_{2}$ capture. Three exemplar thermally modulated fiber sorbents (zeolite 13X and the MOFs UiO-66 and MIL-101(Cr)) are considered to provide insight into the sorbent properties that are most desired for such a process configuration.

Figure 1. Simplified flowsheet describing the sub-ambient $\mathrm{CO}_{2}$ capture process. Blue and purple arrows indicate $\mathrm{N}_{2}$-rich and $\mathrm{CO}_{2}$-rich products of separation. Red arrows indicate the flow of heat. The gold box refers to a $\mathrm{N}_{2}$-enriched Open Refrigeration Cycle. The navy box shows the $\mathrm{CO}_{2}$ separation and purification. Compressors and expanders are shown as one stage for clarity, and possible boiler feedwater (BFW) integration is noted to be supplemented with cooling water.

\section{Methods}


A process model was created in Aspen Plus. Examples of the overall flowsheet are shown in Figure 2, and Figures S1 and S2. The Volume Translated Peng-Robinson equation of state (VTPR) property set was used throughout the $\mathrm{CO}_{2}$ capture process, while the International Association for the Properties of Water and Steam 1995 (IAPWS-95) property set was used to model the generation of BFW preheater steam using available heat from the pulverized coal power cycle. DOE Case 11a from Cost and Performance Baseline for Fossil Energy Plants Volume $1^{34}$ for post-combustion $\mathrm{CO}_{2}$ capture from a supercritical pulverized coal power plant was used as a model baseline for the $\mathrm{CO}_{2}$ product feed. For this analysis, the flue gas composition was simplified to only include $\mathrm{CO}_{2}, \mathrm{~N}_{2}$, and $\mathrm{H}_{2} \mathrm{O}$. The $\sim 1 \%$ other contaminants $\left(\mathrm{O}_{2}\right.$ and $\left.\mathrm{Ar}\right)$ were not considered in the analysis and were grouped in with $\mathrm{N}_{2}$. The expected inlet composition and conditions of the flue gas acting as the inlet to the process are in Table $\mathrm{S} 1$ stream 1. The final conditioned $\mathrm{CO}_{2}$ is delivered at pipeline conditions (35 degC and 120 bar).

Within the process model several assumptions were made, which are outlined in more detail in the Supporting Information. Pressure drops through heat exchangers in this preliminary analysis were taken as 0.1 bar, while the pressure drops through the pressure driven separation unit (membrane or adsorbent) was taken as 0.2 bar. The adsorbent drier bed, pressure-driven separation unit, and the downstream vacuum pump were assumed to operate isothermally. The vacuum pump was modeled as a compressor followed by a heater to simulate the operation of an actual isothermal vacuum pump, as Aspen Plus does not have a built-in vacuum pump model. System compressors and expanders acting on the feed and $\mathrm{N}_{2}$ rich product were assumed axial compressors operating at a $90 \%$ polytropic efficiency sharing a common driveshaft. The volumetric flow rates of flue gas entering the system are on the scale where axial compressors would be viable, and polytropic efficiencies ranging from $88-92 \%$ are typical for these systems. ${ }^{35}$ The vacuum pump, liquefaction compressor, and recycle pressure changer (compressor or turbine depending on the required pressure change) were not in the required size range for axial compressors, so centrifugal compressors were considered instead.

Capital costs for all major equipment were estimated using common cost estimation tools, discussed in further detail in the Supporting Information S2.1. A five year equipment lifetime was taken as basis, and an escalation factor of two was employed to adjust for installation cost. The coal plant was expected to be operational 350 days a year, with an $85 \%$ capacity factor. A levelized cost of electricity of $\$ 0.04 / \mathrm{kWh}$ was used to estimate the energy cost for calculating the total cost per tonne of captured $\mathrm{CO}_{2}$. Cost estimation of composite fiber sorbent module construction is outlined in the Supporting Information S2.2 for MOF and zeolite fiber sorbents containing microencapsulated phase change materials for local heat management.

\section{Sorbent Performance Estimation}

Adsorption equilibrium information is a fundamental resource to evaluate the performance of sorbent candidates for application at process scale. ${ }^{36}$ We estimated $\mathrm{CO}_{2}$ and $\mathrm{N}_{2}$ single-component adsorption isotherms by Grand Canonical Monte Carlo (GCMC) simulations ${ }^{37,38}$ in UiO-66 and MIL-101(Cr). This technique has been extensively used to estimate the adsorption properties of $\mathrm{CO}_{2}$ and similar species in a range of porous sorbent materials. ${ }^{39-44} \mathrm{GCMC}$ simulations were carried out at a range of operating conditions for which we performed design calculations, i.e., sub-ambient temperatures ranging from 213 to $273 \mathrm{~K}$. The details of molecular modeling are provided in the Supporting Information S4.1.1. We then employed Ideal Adsorbed Solution Theory (IAST) ${ }^{45}$ to predict the bulk 0.14:0.86 $\mathrm{CO}_{2}: \mathrm{N}_{2}$ mixture adsorption equilibrium. IAST predicts the mixture equilibrium from single-component adsorption isotherms under the assumption that an ideal solution is formed by the adsorbed phase. ${ }^{46-48} \mathrm{H}_{2} \mathrm{O}$ was not considered in mixture equilibrium assuming only a trace amount remains in a feed into the separation unit after pretreatment of the flue gas. The mixture isotherms were used to estimate sorbent performance via the full-order model outlined below for fiber sorbents with heat management. For zeolite 13X, we applied the extended dual-site Langmuir (DSL) model reported by Haghpanah et al. ${ }^{19}$ (Table S10) for $\mathrm{CO}_{2}: \mathrm{N}_{2}$ mixture equilibrium evaluation.

A fixed-bed packed with thermally-modulated fiber composites ${ }^{31,32}$ was used for modeling of a pressure swing adsorption (PSA) cycle. A complete account of details describing this model can be found in Rubiera Landa et $\mathrm{al}^{49}$ and the Supplemental Information S4.1.2. The cycle employed for the VPSA process consists of four steps: 1. light product pressurization, 2. adsorption, 3. co-current blowdown, and 4. counter 
current evacuation. To compute Pareto frontiers efficiently the VPSA-cycle simulation is treated as a blackbox and the multi-objective optimization algorithm 'Surrogate Optimization of Computationally Expensive Multiobjective Problems' (SOCEMO), developed by Muller ${ }^{50}$ was implemented in Matlab. ${ }^{51}$ This optimizer allows computation of Pareto frontiers at a fraction of the computational cost required for other commonly applied genetic algorithms. ${ }^{52}$ The Pareto frontier values (purity, recovery, system operating conditions) were integrated into the Aspen Plus process model to simulate performance of different adsorbent and cycle design choices. ${ }^{19}$

\section{Results and Discussion}

\section{Sub-ambient $\mathrm{CO}_{2}$ Capture via Heat Integrated Multi-stage Separa- tion}

Hybrid separations like the one considered here have a variety of operating conditions that may be varied to boost the performance of the separation. Operating a PSA or membrane system at higher pressures, lower levels of vacuum, or different temperatures can have wide ranging effects on performance. This discussion focuses on the direct effects of changing these parameters on the economics and energetics of the process assuming the separation performance is held constant. The overall process flowsheet is first described in some detail, after which, the sensitivity of the $\mathrm{CO}_{2}$ capture process energetics are discussed in detail as they relate to four important operating conditions: 1. primary separator high pressure condition, 2. primary separator vacuum condition, 3. primary separator temperature, and 4. liquefaction pressure. The first three variables play a major role in the size and performance of the primary separator. The liquefaction pressure is the key parameter controlling the system temperature profile when overall system recovery is held constant.

\section{Flowsheet Description}

The overall process shown in Figure 2 can be considered in four subsections: 1. gas treatment and energy recovery, 2. sub-ambient heat exchange, 3. pressure driven $\mathrm{CO}_{2}$ separation, and 4. product liquefaction. Figure 2 shows one exemplar separation process which could be utilized, a VPSA unit. A second version of this flowsheet is reported in Figure S1 for process configurations where the liquefaction pressure exceeds the separator operating pressure. In that configuration, one of the compressors (COMP4) is replaced with a turboexpander (TURB3) and its feed is passed through the sub-ambient heat exchanger network prior to expansion. The complete flow sheet including all unit operations for the case shown in Figure 2 is given in Figure S2, with its accompanying stream table reported in Table S1. Specific values discussed throughout this section come from this flowsheet and accompanying stream tables.

An important feature of this design is the fact that it enables steady-state operation, including the secondary liquefaction-based separation without the need for any external cooling utility beyond cooling water. This is similar to the Linde cryogenic distillation case for air separations ${ }^{53-57}$ in this process, mechanical compression and expansion provide the cooling for the process and sufficient driving force to enable the separation. Variation of process conditions to enable a reasonable minimum temperature approach and those subsequent effects on energetics and economics are considered in the following discussion.

\section{Gas Treatment and Energy Recovery}

The flue gas treatment and energy recovery section of the flowsheet performs on water removal and compression of the flue gas and expansion of the $\mathrm{N}_{2}$-enriched product of the separator. Ideally, these expansion and compression systems will share a joint driveshaft to reduce mechanical efficiency losses. The compression of the flue gas feed to the target condition is carried out via two-stage compression, with pressure ratios between 3 and 5 . Multiple intercoolers are used to make the compression more efficient while also providing boiler feed-water (BFW) preheating for the plant. Further discussion of BFW integration can be found in the Supporting Information S1.2. Using just the first stage of compression, the heat for the first three boiler feed-water preheaters is provided as modeled in comparison to DOE Base Case 11a. ${ }^{34}$ Cooling water can 
then be used to cool the feed gas. The compressed gas can be further cooled between compression stages using excess low quality $(>0 \operatorname{deg} \mathrm{C})$ cooling available from the product and byproduct gas. Following the second compression stage, the gas is cooled to $2 \operatorname{deg} \mathrm{C}$ to further dehydrate the gas prior to the complete drying necessary to enter the sub-ambient heat exchange system.

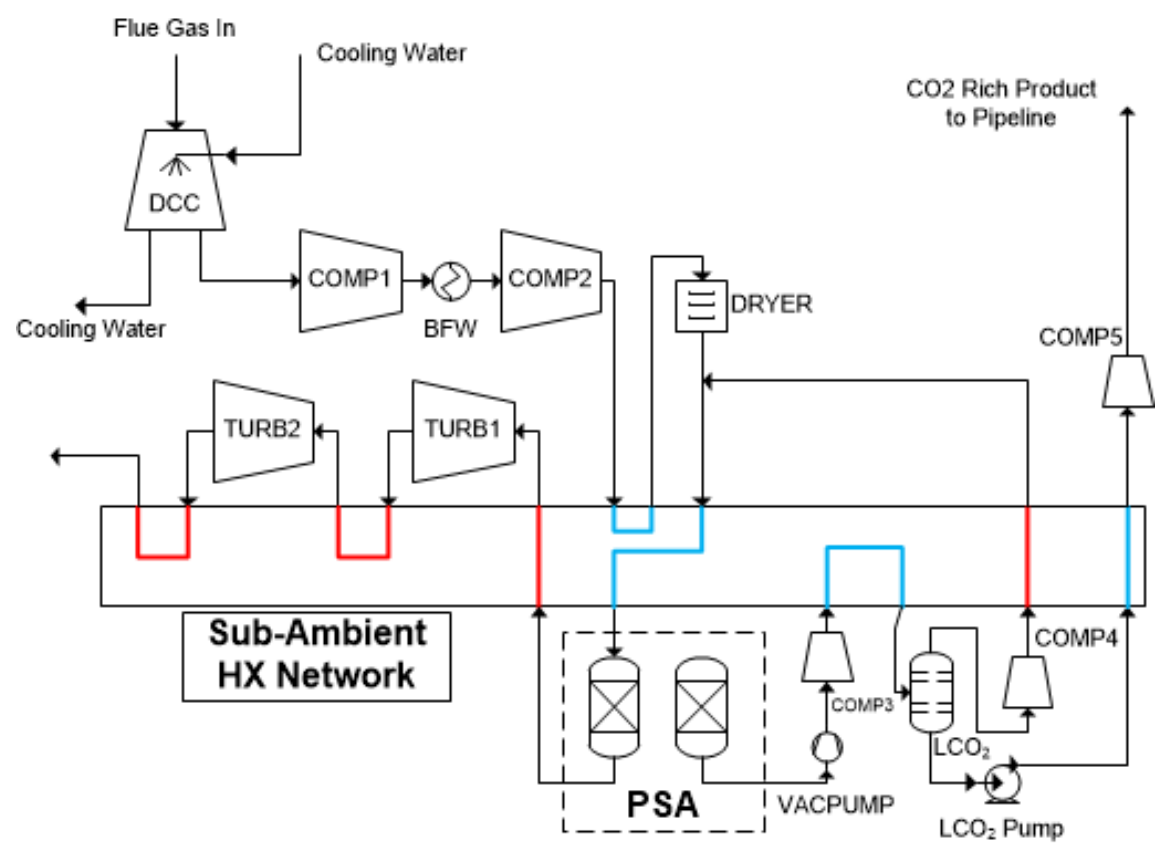

Figure 2. Simplified process flow diagram for a sub-ambient hybrid $\mathrm{CO}_{2}$ capture process using pressure swing adsorption and product liquefaction. Intermediate heat exchangers on the primary compression train using cooling water are not included for the sake of simplicity. A direct contact chiller (DCC), utilizing plant cooling water is used for preliminary water removal. Blue lines in the sub-ambient heat exchanger network indicate streams that are being cooled, while red lines are those being heated.

\section{Power Recovery}

As noted above, compression of the feed and subsequent expansion of the high-pressure $\mathrm{N}_{2}$ byproduct enables the cooling process. The process is therefore highly reliant on the ability to recover the maximum allowable energy via the expansion of this byproduct. In the base case considered, the energy demand for compression is 298.5 MW, a very significant parasitic load. With the inclusion of gas expansion that number is reduced to 207.1 MW. The compression work required is the dominant contribution to the parasitic energy demand on the coal plant. The energy required for the drying of the feed stream and the cooling throughout the process is provided through Joule-Thomson cooling and heat integration, allowing for no additional external energy requirement for the process outside of compression and pumping.

The flowsheet in Figure 2 employs five compressors (two upstream for flue gas, three downstream for liquefaction, recycle, and reaching pipeline pressure specifications respectively), and two expanders (acting on the $\mathrm{N}_{2}$ enriched product). The downstream compressors (COMP3, COMP4, and COMP5), along with the vacuum pump and the liquid $\mathrm{CO}_{2}$ pump have no path for power recovery. Combined, they make up approximately $63.6 \mathrm{MW}(21.3 \%)$ of the electrical demand of the process in the base case. The remaining 143.5 MW of energy is the balance of the compression work that could not be recovered via expansion of the $\mathrm{N}_{2}$ product. Thus in the base case, $\sim 39 \%$ of the work for compression of the flue gas was recovered via expansion. 


\section{Flue Gas Drying}

The drying of flue gas for post-combustion $\mathrm{CO}_{2}$ capture process incurs high energy demands and is thus often considered impractical. ${ }^{22-24}$ If flue gas can be dried, however, the options available for $\mathrm{CO}_{2}$ capture broaden considerably. In our process, flue gas drying is carried out in three stages, first using cooling water from the plant, then taking advantage of Joule-Thomson cooling from the sub-ambient process, and finally, an adsorbent dryer bed. We expect the water from the first two drying stages to be recovered and sent to a cooling tower where it can be returned to the desired conditions. We assume that cooling water at $30^{\circ} \mathrm{C}$ is used to remove the water before compression through the application of a direct contact chiller (DCC). The removal of as much water as possible before compression decreases the total volume of gas that must be compressed, which ultimately reduces the volume of gas to be compressed by $\sim 10 \%$. Removal of water is also vital when using axial compressors, as the condensation of water inside the compressor may damage the airfoils.

Importantly, the sub-ambient process we considered integrates water removal with feed compression and cooling via boiler feed water preheating. This decreases the cost of dehydration that would otherwise be expected if the equivalent energy needed to come from an external source. After the direct contact chiller, compression, and cooling the mole fraction of water in the flue gas stream is estimated in the Aspen model to be $\sim 0.5 \%$, as shown in Table S1. After the flue gas has been compressed to the target pressure, it is cooled to $2^{\circ} \mathrm{C}$ using available cold $\mathrm{N}_{2}$ enriched products as mentioned previously. This additional cooling followed by a knock out decanter results in $528 \mathrm{ppm}$ residual water left in the stream to be removed via the adsorbent. With such a low concentration of water in the flue gas, it is assumed an adsorption dryer will remain essentially isothermal during drying. If the heat integration was unavailable, the economic and energy penalty of the drying would be associated with the cost of drying 10-12 times as much water. Upon completion of its expansion to near atmospheric pressure, the $\mathrm{N}_{2}$-rich product stream is used as a dry sweep gas for the regeneration of the dryer bed and then sent to the stack.

\section{Sub-Ambient Heat Exchange}

Extensive heat integration throughout the process is critical to avoid an expensive external refrigeration utility. The compression of the flue gas upstream is primarily responsible for the process' ability to operate at a steady state with no external refrigeration, as conceptualized in Figure 1. The more the flue gas is compressed, the more high-quality heat removal becomes available from the multistage expansion of the $\mathrm{N}_{2}$ rich byproduct. The base case considers two-stage expansion to produce the required heat removal so the $\mathrm{N}_{2}$-rich product passes through the heat exchanger network three times as seen in Figure 2. This expansioncooling train is responsible for the majority of the following steps: cooling the inlet gas entering the dryer unit, knocking out additional water, cooling the inlet gas to the separation unit, cooling the compressed $\mathrm{CO}_{2}$ enriched product after recompression to the liquefaction condition, and liquefying the $\mathrm{CO}_{2}$ enriched product. In all cases considered, the minimum temperature approach of the process heat balance was determined by the combination of the primary separation final purity and recovery and the liquefaction temperature and pressure. All cases discussed in the following discussion had a fixed recovery of $92 \%$ in the primary separation system to enable an overall system recovery of $90 \%$.

Pressure Driven $\mathrm{CO}_{2}$ Separation

The primary separation for the process is performed by a pressure difference driven separation unit (membrane or PSA) that pre-purifies at high recovery the flue gas to a $\mathrm{CO}_{2}$ rich stream ( $>65 \% \mathrm{CO}_{2}$ Purity, $>92 \%$ $\mathrm{CO}_{2}$ recovery) that is then recovered at vacuum pressures (membrane permeate or PSA vacuum product) to be sent to liquefaction. The minimum recovery of the primary separator was selected such that overall system recovery with the liquefaction step and recycle $90 \%$ overall system recovery consistently, as required by US DOE standards. This requirement for process recovery was enforced through all analysis discussed herein. The $\mathrm{CO}_{2}$-rich product from the separator is sent to the liquefaction process, which further purifies it to pipeline specification purities. The $\mathrm{N}_{2}$-rich product, remaining at the high-pressure condition (as the re- 
tentate of a membrane process or the high-pressure products of PSA) is sent to the heat and energy recovery system described previously.

\section{Product Liquefaction}

Hybrid $\mathrm{CO}_{2}$ capture processes that perform the $\mathrm{CO}_{2}$ purification in multiple stages have shown promise as a way to overcome the limitations of existing adsorbent or membrane materials. ${ }^{17,23,58,59}$ While the baseline model assumes the primary separation unit can produce $95 \%$ pure $\mathrm{CO}_{2}$ at $92 \%$ recovery, installation of a liquefaction column when the cooling is available may prove desirable to open up the selection of materials that may not otherwise be able to reach the final target conditions. The proposed process uses a $\mathrm{CO}_{2}$ liquefaction column primarily to allow for more flexible decision making with materials and process design in the first separator.

Figure S3 shows the overall heat balance for the sub-ambient $\mathrm{CO}_{2}$ capture process at one baseline condition. For the sake of clarity, the cooling water used in the process is not shown. In the base case, the minimum temperature approach $\left(5^{\circ} \mathrm{C}\right)$ occurs at the bubble point $\left(\mathrm{T}_{\mathrm{B}}\right)$ liquefaction column. With 16 bar compression, this case resulted in an excess warming requirement of $>21 \mathrm{MW}$ in the $12-48^{\circ} \mathrm{C}$ range. In this analysis, that excess warming of the product $\mathrm{N}_{2}$ stream is unused and thus is vented to the environment via the stack.

\section{Sensitivity of Operating Conditions}

Four important operating conditions that will affect material selection and performance were identified: the primary separator feed pressure, the primary separator vacuum pressure, the primary separator operating temperature, and the liquefaction pressure. Exploring the effects of varying these process parameters gives insight into the desired properties of the separation unit as well as performance tradeoffs that exist. The effects of the primary separator performance when operating conditions are held constant are discussed in detail in following section (Sub-ambient Pressure Swing Adsorption for $\mathrm{CO}_{2}$ Capture). Since the pressure driven separation could be achieved with either a membrane or adsorption system, discussion of the economics of the primary separator itself is carried out separately.

The sensitivity of these four process conditions was examined with the other three held constant at the baseline levels listed in Table 1. Heat balance of the plant and pinch analysis were not optimized in this analysis except for the baseline case, as these considerations are best meant for optimization cases requiring knowledge regarding the specific separation modality. The effects of purity as it related to the cost of the separation unit are discussed in more detail in later discussions but are also considered for all of these variables as well in S3 of the Supporting Information. In cases where the purity had a non-linear interaction with other variables on the energetics or economics, such effects are also discussed herein. Table 1 also gives the relevant performance parameters of the primary separator.

Table 1. Base case parameters used in the sensitivity analysis

\begin{tabular}{ll}
\hline Base Case Condition & Value \\
\hline Separator Operating Pressure & $16 \mathrm{bar}$ \\
Operating Temperature & $-30{ }^{\circ} \mathrm{C}$ \\
Separator Vacuum Pressure & $0.2 \mathrm{bar}$ \\
Liquefaction Column Pressure & $14 \mathrm{bar}$ \\
Separator $\mathrm{CO}_{2}$ Product Purity & $95 \%$ \\
Separator $\mathrm{CO}_{2}$ Recovery & $92 \%$ \\
System $\mathrm{CO}_{2}$ Recovery & $90 \%$ \\
\hline
\end{tabular}

\section{Primary Separator Feed Pressure}

The level of flue gas compression before the separation affects two main performance metrics. First and most importantly, higher compression requires more energy. Figure 3a shows the relationship between 
compression and process energy requirement $\left(\mathrm{kWh} /\right.$ tonneCO $\left.\mathrm{C}_{2}\right)$ on the capture process. As more compression is required from the process, the compressors become larger and require more energy, resulting an expected increase in energy cost per tonne of $\mathrm{CO}_{2}$. The trend, normalized to the baseline power requirement of $403.1 \mathrm{kWh} /$ tonneCO $\mathrm{CO}_{2}$, appears fairly linear, which may be expected. However, depending on the separation process and materials, additional compression may allow for a more effective separation (higher $\mathrm{CO}_{2}$ purity, recovery, and productivity/fluxes) at the cost of this additional energy demand but an ultimately lower cost of $\mathrm{CO}_{2}$ capture.

Increases in the required compression also necessitate an increase in the size of three of the four compressors in the system resulting in a higher capital cost (Figure S9). This cost may be partially offset with the size reduction of other system components, like piping, whose size is in part determined by the volumetric flow rate; this is not accounted for in this preliminary cost study. Compression is a vital part of the ability of the process to operate without an external cooling utility, as previously discussed. Beyond a certain level of compression, the amount of cooling available via Joule-Thomson cooling cannot provide the required heat removal. In this scenario, there is no simple way to adjust the process design (e.g., changing the expander pressure ratio will not allow for more cooling to become available) to provide more cooling to the process. While we do not observe this in cases where the operating pressure is 6 bar or above it is conceivable such situations may arise.

\section{Primary Separator Operating Temperature}

Figure $3 \mathrm{~b}$ shows the effect of decreasing the operating temperature of the separator on the overall energy demand of the process. As the operating temperature decreases the overall system energy requirements decrease, while the total amount of heat removal required increases. This increase in required cooling ultimately does not impact the energy demand of the process on the plant due to the significant levels of heat integration and recovery. Across all separation system temperatures considered we estimated that there was at least $18.5 \mathrm{MW}$ of excess heat removal capabilities available at low qualities $\left(-5\right.$ to $\left.30^{\circ} \mathrm{C}\right)$. The decrease in energy instead is due to a slight reduction in the required energy of the liquefaction compressor (in COMP3 in Figure 2) as the compressor receives a lower temperature inlet gas. The economic analysis for the process shows a similarly small reduction in the cost of capture with lower temperatures, where the cost of the additional heat exchanger area is offset almost entirely by the reduction in monetized energy demand on the plant (Figures S10 and S11).

\section{Primary Separator Vacuum Pressure}

The vacuum pressure used to recover the $\mathrm{CO}_{2}$-rich product leaving the separator was varied from 0.05 to 0.3 bar. With these moderate levels of vacuum we assumed a vacuum efficiency of 0.8 for an isothermal vacuum pump. Since the vacuum pump is somewhat isolated from the rest of the process, a variation of the vacuum pressure results follows a logarithmic profile with respect to energy as shown in Figure 3c. The lower the purity at the designated recovery, the more the volume of gas that needs to be removed via the vacuum, resulting in higher cost (see Figure S12).

\section{Liquefaction Pressure}

From an electrical energy and cost perspective, there is a moderate effect on increasing the liquefaction pressure, as shown in Figure 3d and Figure S13a, respectively. This increase is primarily due to the increase in the size of the compressor used for liquefaction. The increase is slightly reduced as the liquefaction pressure approaches the separator operating pressure due to the necessity for less work in the recycle compressor. The primary effect of the choice of liquefaction pressure is on the temperature the liquefaction column requires for the $90 \% \mathrm{CO}_{2}$ recovery condition set as a requirement for the process. These temperature effects across a wide range of separation performance (purity) conditions, are given in Figure S13c. This choice, therefore, has considerable effects on the design of the final heat exchanger network, as well as the ability of the plant to utilize the process' available heat removal with a reasonable temperature approach. 


\section{Sub-ambient Pressure Swing Adsorption for $\mathrm{CO}_{2}$ Capture}

As the economics of a membrane-based process have already been considered in some detail in the work of Hasse et $a l,{ }^{26,27}$ it is interesting to explore the performance of a PSA separation in the sub-ambient capture process. A simple four-step cycle for heavy-product recovery (pressurization, feed, blowdown, and evacuation) was considered for baseline performance. For preliminary analysis of the economics of $\mathrm{CO}_{2}$ capture, we assumed a 2-bed system with a $360 \mathrm{~s}$ cycle time $(180 \mathrm{~s}$ on pressurization and feed, $180 \mathrm{~s}$ on

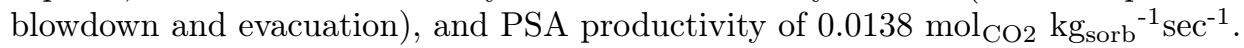

a)

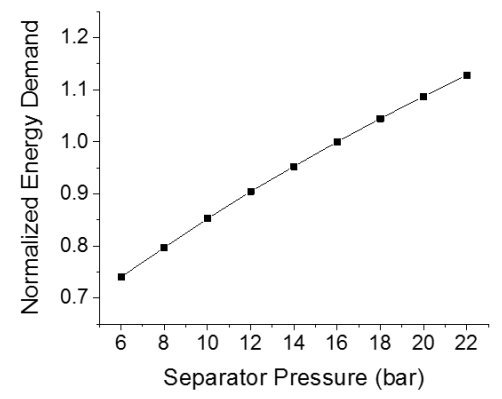

c)

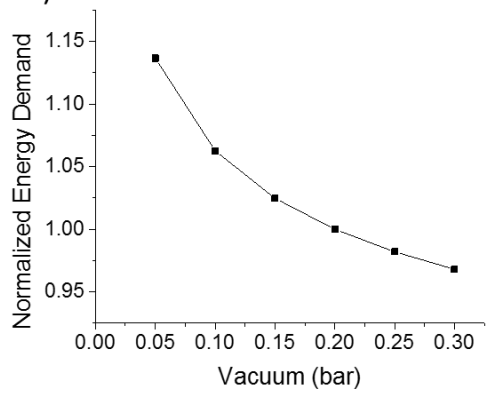

b)

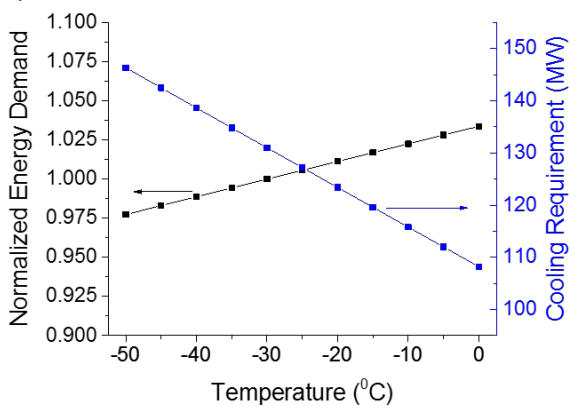

d)

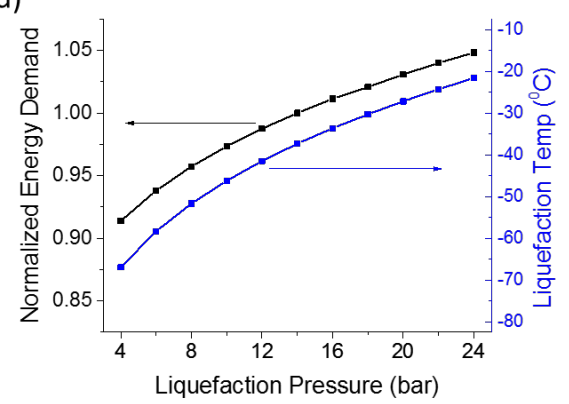

Figure 3. Effects on overall energy demand for $\mathrm{CO}_{2}$ capture $\left(\mathrm{kWh} /\right.$ tonneCO $\mathrm{O}_{2}$ normalized, where base case is $403.1 \mathrm{kWh} /$ tonne $\mathrm{CO}_{2}$ ) and other relevant process conditions while varying (a) separator feed pressure, (b) separator operating temperature (blue: net heat removal process requirements), (c) separator vacuum pressure, and (d) liquefaction pressure (blue: minimum temperature of liquefaction column). All variations are with respect to the base case listed in Table 1.

Two significant physical phenomena must be considered when considering operating a PSA system for this process, the heat of adsorption and the pressure drop. Structured sorbent contactors can help address the challenges associated with these phenomena. Structured contactors can reduce pressure drop greatly ${ }^{32,60}$ and also fully manage or at least limit thermal effects in the bed. ${ }^{31-33,61}$ Using a fiber morphology, similar to those used in membranes, but with the polymer skeleton filled with sorbent particles, we can accomplish the same sorts of very low pressure drops experienced in hollow fiber membranes. ${ }^{32,60}$ To manage the heat of adsorption, which can be significant in high productivity beds with high operating capacities, the fiber sorbent bed can also incorporate microencapsulated phase change materials $(\mu \mathrm{PCM}) .{ }^{31}$ While fiber sorbent contactors have not yet been used industrially, their manufacturing process mimics that of both textile fibers and fiber membranes, so it is reasonable to expect their transition to application in adsorptive separations is feasible if they bring significant advantages.

The cost of fiber sorbent contactors containing phase change materials has not previously been considered in detail. Fiber beds were estimated to be made up of a multitude of individual fibers (diameter $650 \mu \mathrm{m}$, length 1 $\mathrm{m})$. The weight ratio of phase change material to sorbent was taken at 1.25:1. The cost of the fibers was broken 
down into three parts, the price of the sorbent (base case economics take this value as $\$ 30 / \mathrm{kg}$ ), the price of $\mu \mathrm{PCM}(\$ 10 / \mathrm{kg}$, based on an estimate from an industrial manufacturer $)$, and the cost of the manufacture of the fibers and fixing them in flow modules $\left(\$ 20 / \mathrm{m}^{2}\right.$ fiber external surface area). The manufacturing cost was estimated from the price of industrial hollow fiber membranes, which are also produced using dry-jet wet-quench techniques. Figure 4 shows the estimated breakdown in the cost of manufacturing the PSA unit containing fibers with phase change materials for our baseline case as a function of sorbent price. Across all considered sorbent costs, the price of manufacturing the fibers and potting them in modules dominates. Even in cases where the sorbent price is high $(\$ 100 / \mathrm{kg})$, the device manufacturing costs rather than the material costs still make up the majority of the total cost. The effects of fiber diameter, the relative loading of phase change materials and sorbent loading on the overall cost of the separator is discussed in greater detail in S2.2 of the Supporting Information.

\section{Hosted file}

image3.emf available at https://authorea.com/users/386891/articles/502288-analysis-ofenergetics-and-economics-of-sub-ambient-hybrid-post-combustion-co2-capture

Figure 4. Cost breakdown of PSA fiber module manufacturing for a MOF- $\mu$ PCM-polymer fiber sorbent module with 75 wt. \% solids loading and a 1:1.25 mass ratio of MOF: $\mu \mathrm{PCM}$ at varying cost of the sorbent.

Using the idealized cycle design (360 s cycle time) we estimated the cost of $\mathrm{CO}_{2}$ capture using a sub-ambient sorbent for a wide range of sorbent productivities and $\mathrm{CO}_{2}$ purities leaving the PSA unit. Figure 5 shows the effect of sorbent productivity and product $\mathrm{CO}_{2}$ purity on the overall cost of capture. The cost of capture is significantly less sensitive to sorbent productivity at productivities greater than $0.015 \mathrm{~mol} \mathrm{~kg}^{-1} \mathrm{~s}^{-1}$. Around this value the cost of the PSA unit is less than $25 \%$ of the total capital cost so the capital cost is dominated by the energy demand of the process and the other capital equipment.

An interesting implication of Figure 5 is that varying the rich product purity from the PSA unit leads to only minor variation in the total cost of $\mathrm{CO}_{2}$ capture. Reducing the $\mathrm{CO}_{2}$ rich product purity from the PSA unit to values from $85 \%$ to $75 \% \mathrm{CO}_{2}$ showed a $\$ 1.00-\$ 1.20 /$ tonne $\mathrm{CO}_{2}$ increase in total capture cost. This change stems from an increase in the size and energy requirement of the liquefaction system for the reduced purity case. Reducing the purity also leads to increased energy demand due to a reduction in the amount of expansion energy that can be recaptured. This analysis can offer some insights into the economic tradeoffs of slight improvements in productivity at the cost of purity. As an example for a situation where two theoretical adsorbents are considered, a PSA operating with one sorbent may give PSA purity of $95 \%$ and productivities of $6.66 \times 10^{-3} \mathrm{~mol} \mathrm{~kg}^{-1} \mathrm{sec}^{-1}$ with a resulting cost of capture of $\$ 88 /$ tonne $\mathrm{CO}_{2}$. A second adsorbent, one which could only produce $75 \%$ purity would only achieve a similar cost of capture with productivities about 1.25 times higher $\left(8.33 \times 10^{-3} \mathrm{~mol} \mathrm{~kg}^{-1} \mathrm{sec}^{-1}\right)$ to have a similar overall cost of capture.

\section{Hosted file}

image4.emf available at https://authorea.com/users/386891/articles/502288-analysis-ofenergetics-and-economics-of-sub-ambient-hybrid-post-combustion-co2-capture

Figure 5. The effect of sorbent productivity $\left(\mathrm{mol}_{\mathrm{CO} 2} \mathrm{~kg}_{\mathrm{sorb}}{ }^{-1} \mathrm{sec}^{-1}\right)$ on the overall cost of capture at baseline operating conditions (Table 1) with (black) $95 \%$, (red) $85 \%$ and (blue) $75 \% \mathrm{CO}_{2}$ purity resulting from the PSA unit. Cost of capture approaches $\$ 47.12$ asymptotically with respect to increasing productivity.

\section{Sub-ambient Fiber Sorbent PSA}

Analysis of the PSA separation process thus far has focused on the effects of a single parameter in the $\mathrm{CO}_{2}$ capture process. This analysis can help guide decisions when considering a particular sorbent. But to better understand the process more broadly, it is imperative to understand how changing multiple variables simultaneously effects the process simultaneously. The separation performance of three sorbent materials was considered. 
UiO-66 and MIL-101(Cr) are two MOFs that show some promise for sub-ambient $\mathrm{CO}_{2}$ capture. ${ }^{36,41}$ Both materials are stable in liquid water, which is a prerequisite for their spinning into heat managed fiber sorbent structures. In addition, both materials have shown the ability to be scaled up to the 10-1000 g batch scale. ${ }^{62}$ The use of UiO-66 as a sorbent for sub-ambient $\mathrm{CO}_{2}$ capture has been briefly discussed elsewhere, where an operating capacity of $4 \mathrm{mmol} / \mathrm{g}$ at $243 \mathrm{~K}$ was shown. ${ }^{31}$ While MIL-101(Cr)'s sub-ambient performance has not been reported, its crystalline structure with very large pores $(1.4 \text { and } 2.2 \mathrm{~nm})^{63}$ meets a material selection criteria as suggested elsewhere ${ }^{41}$ that makes it promising for having high working capacity. Enabling these sorts of high working capacities is expected to be one of the key benefits to this sub-ambient process, enabling the very high productivities shown to be highly desirable in Figure 5.

UiO-66 has been spun into fiber sorbents previously ${ }^{31,64}$ while MIL-101(Cr) shows promise for such spinning, with its good aqueous and chemical stability. ${ }^{65}$ Proof of concept sorbent spinning with microencapsulated phase change material, $\mu \mathrm{PCM}$, was carried out with UiO-66 sorbents previously, ${ }^{31}$ and the methods applied should be easily generalizable to other solid sorbent systems.

The performance of these two MOF sorbents and zeolite 13X, a common sorbent considered for postcombustion $\mathrm{CO}_{2}$ capture via PSA ${ }^{23,66,67}$, for a sub-ambient PSA was investigated using dynamic process simulations. To confirm the necessity of the downstream liquefaction, this was first carried out at feed conditions consistent with a process without downstream liquefaction and recycle $\left(14: 86 \mathrm{CO}_{2}: \mathrm{N}_{2}\right)$. The Pareto frontiers calculated for these materials at two temperatures $(273 \mathrm{~K}$ and $298 \mathrm{~K}$ for $13 \mathrm{X}$, and $243 \mathrm{~K}$ and 273 $\mathrm{K}$ for the MOFs) are reported in Figure S15 with the corresponding process and fiber parameters are reported in Tables S15-S20. None of the sorbents considered were capable of reaching the performance goal of $95 \%$ purity and $90 \%$ recovery without liquefaction, so a hybrid system including liquefaction as a secondary purification step appears to be necessary for these sorbents.

Zeolite 13X (Figure S15) showed superior performance at $298 \mathrm{~K}$ than at $273 \mathrm{~K}$. The results at $273 \mathrm{~K}$ were unable to reach the required $\mathrm{CO}_{2}$ product recovery for the PSA of $92 \%$ to enable the required overall system $\mathrm{CO}_{2}$ recovery of $90 \%$, making this material undesirable for the sub-ambient PSA process. It is worth noting that at $298 \mathrm{~K}$ condition the productivities of the thermally managed 13X fiber sorbent PSA are expected to be 6-7 times higher than that of comparable pellet based systems. ${ }^{19,66,68}$ With this performance improvement in mind, the flowsheet discussed throughout the prior sections of the manuscript was reconfigured to enable an ambient PSA process while still allowing for the removal of water and liquefaction of the $\mathrm{CO}_{2}$ rich product via Joule-Thompson expansion. The relevant flowsheet and preliminary economic estimates for the best-case scenario are reported in the Supporting Information (S4.4). Stated briefly, zeolite 13X fiber sorbents with thermal modulation operating at $298 \mathrm{~K}$ appears to be economically competitive with the sub-ambient MOF fiber sorbents, showing somewhat higher cost of capture of $\sim \$ 71 /$ tonne $\mathrm{CO}_{2}$. We leave more in depth analysis of this alternative approach to ambient, elevated pressure $\mathrm{CO}_{2}$ capture to future considerations, as the object of this work has been to understand the possibilities and limitations of the sub-ambient approach. Still, the preliminary analysis in the Supporting Information leads us to believe there is potential in the application of Joule-Thompson cooling combined with water removal, $\mathrm{CO}_{2}$ liquefaction, and PSA processes operating at ambient temperatures and elevated pressures.

\section{Economics of Sub-ambient MOF Fiber Sorbents}

Having established that liquefaction is required to reach the target delivery purity with the MOF sorbents we considered, the Pareto frontiers were recomputed using a 17:83 $\mathrm{CO}_{2}: \mathrm{N}_{2}$ mixture to simulate the inlet to the PSA unit when liquefaction and recycle are employed. The complete Pareto front is given in Figures 6 and S16 with all PSA operating conditions and fiber morphology parameters provided in Tables S21 and S22. An inset in Figure 6 shows the points with $>65 \%$ purity and 92\% recovery. MIL-101(Cr) shows a slightly more desirable Pareto frontier than UiO-66. Both sorbents have a clear tradeoff between the purity and recovery of the sub-ambient PSA unit. Ten separate PSA conditions, five for each sorbent, were used as case studies in the process model discussed. These conditions are indicated in Figure 6 as starred points and their operating conditions, performance, and fiber compositions are listed in Table 2. For each case, the temperature, PSA pressure, PSA vacuum condition, and the PSA product purity and recovery were used 
as conditions within the process model. The heat exchanger system was then optimized to include a $5{ }^{\circ} \mathrm{C}$ temperature approach by varying the liquefaction column pressure. The compressor prior to liquefaction was always kept as a single-stage, which in cases where the pressure ratio exceeded 10 may prove unrealistic and undesirable. In cases where the liquefaction pressure was greater than the PSA operating pressure, the same flowsheet adjustments were made as those described previously. The Temperature-Enthalpy(T-H) diagrams for each of the cases considered are given in Section S4.3 of the Supporting Information.

It is worth noting in Table 2 that both UiO-66 and MIL-101(Cr) show productivities exceeding 0.015 mol $\mathrm{kg}^{-1} \mathrm{sec}^{-1}$, which based on previous discussion should lead to reasonable costs. In all 10 cases considered, the optimizer yielded a result close to the specified lower bound value of the vacuum level for the PSA unit. This suggests there may be room for improvement in the performance of these fiber sorbents if the PSA process could be operated economically at even lower vacuum levels.

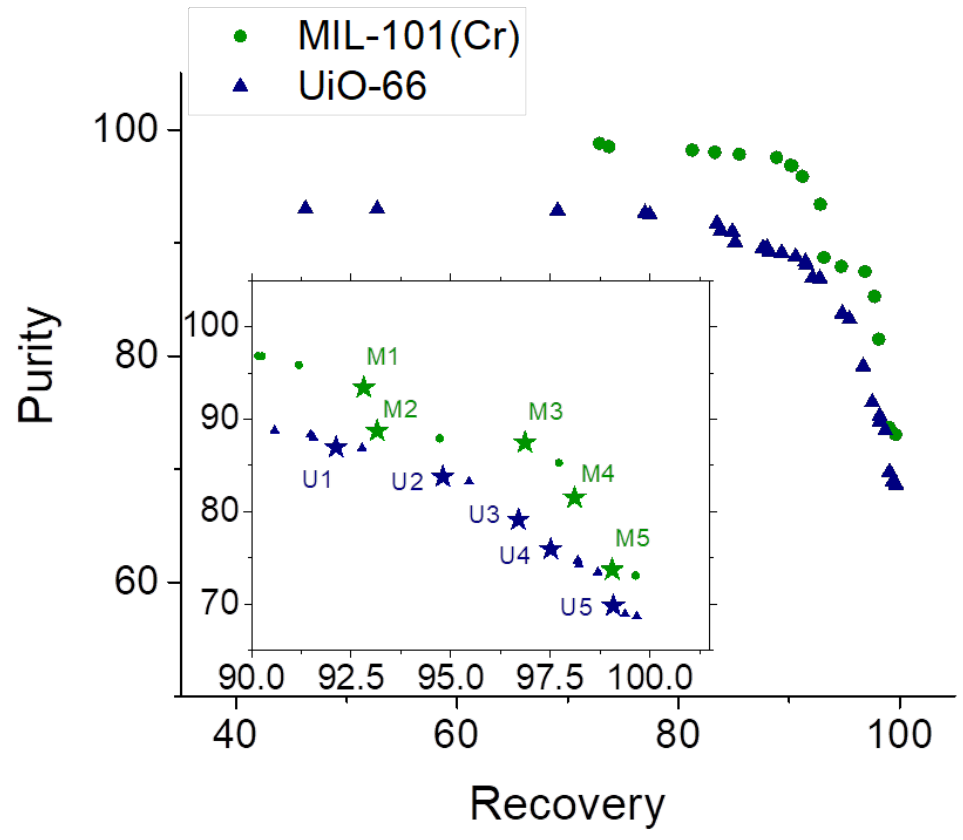

Figure 6. Optimized purity-recovery Pareto frontiers for UiO-66 (blue) and MIL-101(Cr) (green) fiber sorbents for sub-ambient PSA operation at $243 \mathrm{~K}$. The inset shows points within the desired range of purity and recovery. Starred points (with identical color schemes) indicate conditions used in separate case studies.

Table 2. Operating conditions, performance, and fiber compositions used in case studies with pressures in bar and productivity in mol $\mathrm{kg}^{-1} \mathrm{~s}^{-1}$.

\begin{tabular}{llllllllll}
\hline & & $\mathrm{U} 1$ & $\mathrm{U} 2$ & $\mathrm{U} 3$ & $\mathrm{U} 4$ & $\mathrm{U} 5$ & $\mathrm{M} 1$ & M2 & M3 \\
\hline PSA Operating Pressure & PSA Operating Pressure & 12.68 & 14.05 & 12.68 & 15.45 & 12.49 & 20.19 & 18.22 & 20.22 \\
PSA Vacuum Pressure & PSA Vacuum Pressure & 0.10 & 0.10 & 0.10 & 0.12 & 0.11 & 0.10 & 0.10 & 0.10 \\
\% Recovery & \% Recovery & 92.12 & 94.80 & 96.70 & 97.51 & 99.08 & 93.00 & 93.00 & 97.00 \\
\% Purity & \% Purity & 86.95 & 83.77 & 79.12 & 75.93 & 69.80 & 93.00 & 89.00 & 87.00 \\
Productivity & Productivity & 0.0194 & 0.0175 & 0.0160 & 0.0149 & 0.0127 & 0.0327 & 0.0252 & 0.027 \\
Fiber MOF wt\% & Fiber MOF wt\% & 36.8 & 40.0 & 37.7 & 40.0 & 38.2 & 32.4 & 34.7 & 32.2 \\
Fiber uPCM wt\% & Fiber uPCM wt\% & 38.2 & 35.0 & 37.3 & 35.0 & 36.8 & 42.6 & 40.3 & 42.8 \\
\hline
\end{tabular}


Figure 7a shows the cost of capture as a function of the recovery of the PSA unit for the two MOF sorbents. Cost as a function of other PSA performance parameters (productivity, purity) are shown in Figure S17. There is a clear positive correlation between the recovery of the system and the cost of the $\mathrm{CO}_{2}$ capture system. As the recovery goes up so too does the size of the downstream liquefaction and recycle systems. This effect is primarily driven by the amount of gas which has to be compressed during liquefaction but it is also impacted by the $\mathrm{CO}_{2}$ purity from the liquefaction column since higher recoveries are often associated with lower purities.

Figure $7 \mathrm{~b}$ shows the cost $\left(\$ /\right.$ tonneCO $\left.\mathrm{C}_{2}\right)$ comparison for the five MIL-101(Cr) sorbent cases, with each case's cost broken down into its constituent costs (capital and energy). As the recovery increases and the purity decreases, the energy, rotating equipment, and PSA units' costs all increase significantly. The increase in energy and rotating equipment cost mainly comes from the increased amount of gas in the liquefaction process, which drives up the size and energy demand of COMP3. In case M5, the energy demand of that single compressor is greater than the amount of energy produced by the base case plant. The increase in PSA cost relates both to recovery and productivity. With increasing recovery more $\mathrm{CO}_{2}$ must be captured by the PSA, along with slight increases in the amount of $\mathrm{CO}_{2}$ held up in the recycling of the system. Cases M4 and M5 also suffer from 20-30\% reductions in PSA productivity as compared to the lower recovery cases, which will also play a role in the increased price of the PSA unit. A similar analysis on UiO-66 sorbent cases is provided in Figure S18.

As a typical case, the simplified flowsheet for Case M1 is given in Figure 8. The flue gas enters the system and passes through the direct contact chiller, where $97.4 \%$ of water is removed, reducing the concentration of water in the stream to $0.47 \%$. The partially dehumidified gas is then passed through a series of two compressors with intercoolers, where it reaches a target pressure of 20.49 bar. The stream is further cooled down to $2{ }^{\circ} \mathrm{C}$ in the sub-ambient heat exchanger network, where additional water is also removed. This high pressure feed (1) at 20.29 bar contains only $437.6 \mathrm{ppm} \mathrm{H}_{2} \mathrm{O}$, which is removed in an adsorbent dryer. Leaving the adsorbent dryer, the now bone dry flue gas with composition $14.65 \% \mathrm{CO}_{2}$ and $85.35 \% \mathrm{~N}_{2}$ is mixed with the cold recycle (6) which is $81.5 \% \mathrm{CO}_{2}$. This mix (2), a $\mathrm{CO}_{2}$ enriched feed of $18.9 \% \mathrm{CO}_{2}$, is then cooled to the $-30^{\circ} \mathrm{C}$ operating condition of the PSA, entering the system at 20.19 bar.

The $\mathrm{N}_{2}$-rich product in Figure 8 (stream 3), still at a high pressure condition of 19.99 bar, is then cooled and expanded repeatedly, generating streams at temperatures as low as $-93{ }^{\circ} \mathrm{C}$, while also recovering $97 \mathrm{MW}$ of energy. The $\mathrm{CO}_{2}$ enriched product is recovered at 0.103 bar vacuum pressure with a concentration of $\mathrm{CO}_{2}$ of $93.4 \%$. From the vacuum pump it is recompressed to a moderate 12.5 bar pressure before being sent back to the sub-ambient heat exchange network as the feed to the liquefaction column. Operating at $-40.4{ }^{\circ} \mathrm{C}$, the top stream from the liquefaction column is recompressed from the 12.5 bar liquefaction pressure to 20.29 bar where the cold recycle (stream 6) enriches the feed. The liquid $\mathrm{CO}_{2}$ product (stream 7), now $99.6 \%$ $\mathrm{CO}_{2}$, is pumped to the feed condition of the $5^{\text {th }}$ stage of the multistage compression $(63.4 \mathrm{bar})$ and heated to provide heat removal to the rest of the system from $-38{ }^{\circ} \mathrm{C}$ to $35{ }^{\circ} \mathrm{C}$. It can then be compressed to the pipeline condition of 152.7 bar, where it can be transported to storage or sequestration.

a)

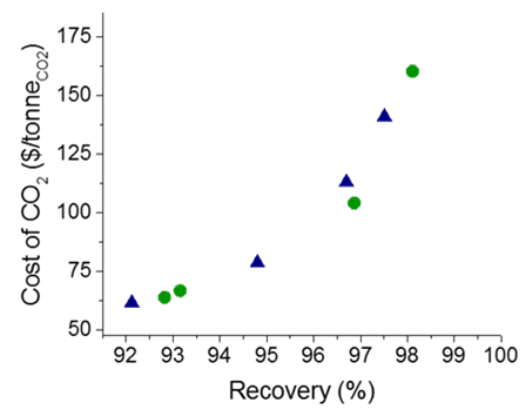

b)

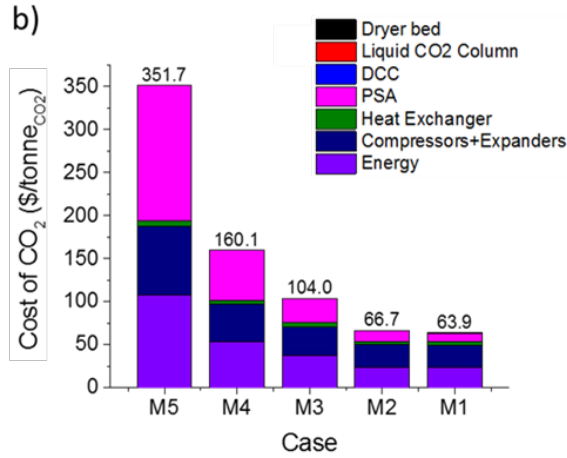


Figure 7. (a) Cost of $\mathrm{CO}_{2}$ capture of 8 different cases studied (case M1-4) MIL-101(Cr), green circles, (Case U1-U4) UiO-66, navy triangles as compared to $\mathrm{CO}_{2}$ recovery of the PSA unit. Cases M5 and U5 were not included to make the figure clear. (b) Cost of capture for the five MIL-101(Cr) cases, broken down into capital and energy costs.

Considering sorbents on the whole for this sub-ambient PSA process, it appears that the main room for improvement will come about by increasing the purity of the $\mathrm{CO}_{2}$ product from the PSA without sacrificing recovery and still showing productivities exceeding $0.015 \mathrm{~mol} \mathrm{~kg}^{-1} \mathrm{~s}^{-1}$. This goal may be reached in a variety of ways, including sorbent design/selection or an improved PSA cycle design. Increasing the selectivity of the sorbent while not sacrificing too much of its capacity for $\mathrm{CO}_{2}$ at sub-ambient conditions would drive the Pareto frontier in Figure 6 to more desirable conditions. Sorbents which could reach the desired purities, recoveries, and productivities shown for MIL-101(Cr) and UiO-66, but not requiring as low a vacuum condition would also be able to drive down the cost. The PSA cycle considered here did not consider any pressure equalization between beds. The inclusion of this feature and similar degrees of freedom for the PSA cycle design may result in further improvements in PSA performance.

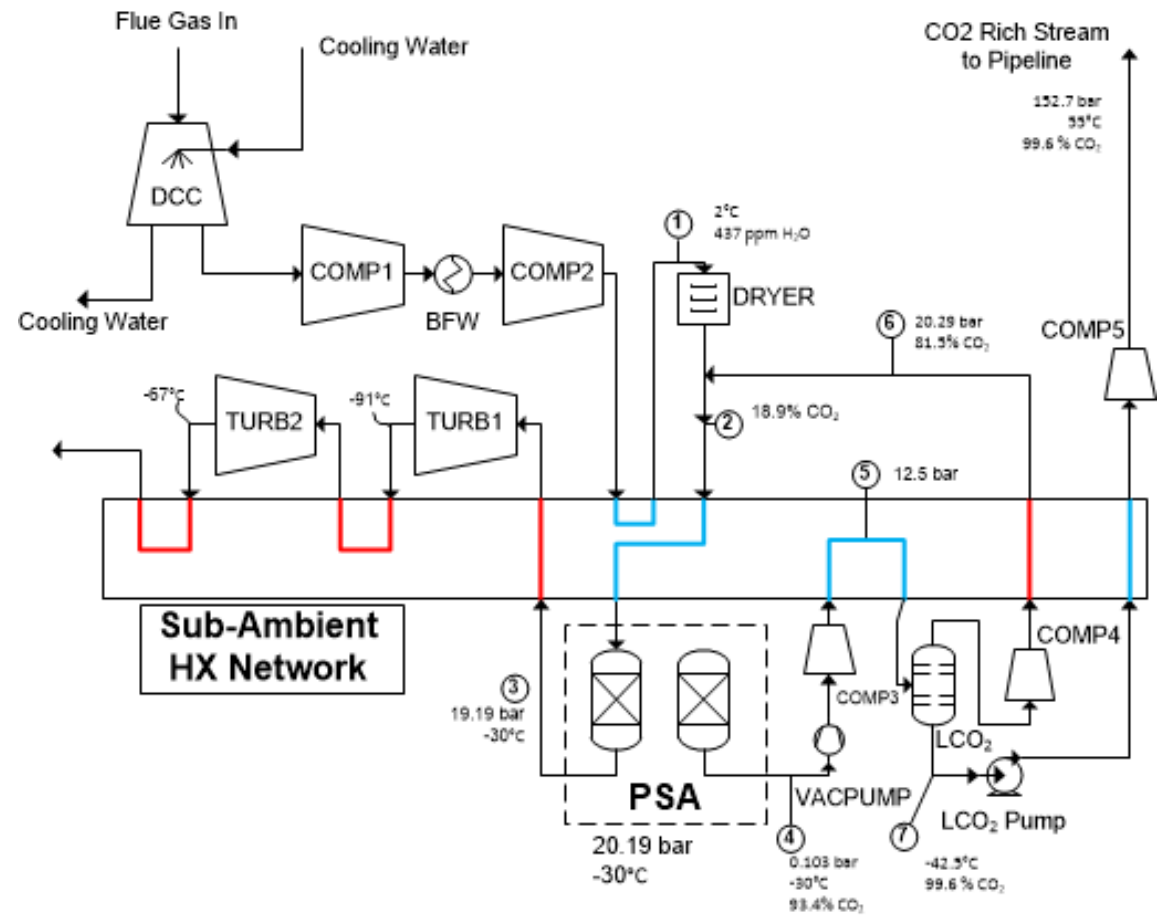

Figure 8. Simplified flow diagram for Case M1. Selected streams are labelled with circled numbers are discussed further in the text.

\section{Conclusions}

A framework for $\mathrm{CO}_{2}$ capture utilizing extensive flue gas pretreatment and $\mathrm{CO}_{2}$ post-treatment focusing on sub-ambient operating temperatures and elevated operating pressures with a post-separation liquefaction column has been considered. As expected, the most significant effect on the performance of the capture system energetics and economics (not accounting for the separation unit) comes from the compression of the flue gas and the efficiencies of the rotating equipment. Pressure swing adsorption (PSA) processes show promise for the first separator in the system, as the cost of the PSA unit tends to be controlled primarily by 
the productivity of the PSA system, and operating at sub-ambient conditions may enable significantly higher productivity with appropriate sorbent selection. The addition of the liquefaction column downstream of the PSA unit allows for sorbents and operating conditions to be considered that would otherwise be eliminated on account of their inability to reach the purities required by pipeline specification.

Structured contactors are an important option for the management of pressure drop and thermal effects, which would otherwise adversely affect performance of the PSA unit. Sorbents considered for traditional $\mathrm{CO}_{2}$ capture via PSA at room temperature such as zeolite 13X may be used in this process, although in the case of $13 \mathrm{X}$ performance is actually reduced when operating at sub-ambient conditions. Two MOF sorbents, MIL-101(Cr) and UiO-66, were considered for application as thermally managed fibers in the sub-ambient PSA and showed costs of capture as low as $\$ 61 /$ tonneCO $\mathrm{C}_{2}$. The tradeoff between PSA product purity and recovery proved to be the key economic parameter of the system once high productivities were reached, as the downstream liquefaction process becomes costly from a capital and energy perspective when high recoveries are combined with low purities.

Our analysis shows there are viable paths to sub-ambient hybrid $\mathrm{CO}_{2}$ capture processes, but high $\mathrm{CO}_{2}$ capture productivities ( $>0.015 \mathrm{~mol} \mathrm{~kg}^{-1} \mathrm{~s}^{-1}$ at $>75 \% \mathrm{CO}_{2}$ purity and $92 \% \mathrm{CO}_{2}$ recovery) are required to make the sub-ambient hybrid separation process economically competitive with other alternatives. Our models of subambient PSA shows that sorbent materials with the potential to show enhanced capacities at the desired high-pressure and low-temperature conditions would show the most improvement, while sorbents like zeolite 13X, which shows more potential at traditional operating conditions, may prove incapable of reaching the require purities and recoveries within the bounds of feasible vacuum levels.

Present Address: Department of Materials Process Engineering, Nagoya University, Nagoya, Japan

\section{Acknowledgements}

The authors acknowledge the U.S. Department of Energy through grant DE-FE0026433 for financial support. Any options, findings, conclusions or recommendations expressed herein are those of the author(s) and do not necessarily reflect the views of the DOE. The authors would like to thank Sun Hye Kim for her helpful discussion and advice on costing of fiber sorbent modules, and Eli Carter for the many discussions of MOF performance at sub-ambient conditions.

\section{Conflict of Interest}

The authors declare no conflict of interest

\section{References}

1. Hope C, Schaefer K. Economic impacts of carbon dioxide and methane released from thawing permafrost. Nature Climate Change.2016/01/01 2016;6(1):56-59.

2. Yu C-H, Huang C-H, Tan C-S. A Review of $\mathrm{CO}_{2}$ Capture by Absorption and Adsorption. Aerosol and Air Quality Research. 2012;12(5):745-769.

3. Kahn B. We Just Breached the $410 \mathrm{PPM}$ Threshold for $\mathrm{CO}_{2}$. Scientific American . Online: Springer Nature; 2017.

4. Pacala S, Socolow R. Stabilization Wedges: Solving the Climate Problem for the Next 50 Years with Current Technologies.Science. 2004;305(5686):968-972.

5. Modak A, Jana S. Advancement in porous adsorbents for post-combustion $\mathrm{CO}_{2}$ capture. Microporous and Mesoporous Materials. 2019/03/01/ 2019;276:107-132.

6. Simmons JM, Wu H, Zhou W, Yildirim T. Carbon capture in metal-organic frameworks-a comparative study. Energy Environ. Sci. Jun 2011;4(6):2177-2185. 
7. To JWF, He JJ, Mei JG, et al. Hierarchical N-Doped Carbon as $\mathrm{CO}_{2}$ Adsorbent with High $\mathrm{CO}_{2}$ Selectivity from Rationally Designed Polypyrrole Precursor. Journal of the American Chemical Society. Jan 2016;138(3):1001-1009.

8. Thiruvenkatachari R, Su S, An H, Yu XX. Post combustion $\mathrm{CO}_{2}$ capture by carbon fibre monolithic adsorbents.Progress in Energy and Combustion Science. Oct 2009;35(5):438-455.

9. McDonald TM, Mason JA, Kong XQ, et al. Cooperative insertion of $\mathrm{CO}_{2}$ in diamine-appended metalorganic frameworks.Nature. Mar 2015;519(7543):303-308.

10. Machida $\mathrm{H}$, Ando $\mathrm{R}$, Esaki $\mathrm{T}$, et al. Low temperature swing process for $\mathrm{CO}_{2}$ absorption-desorption using phase separation $\mathrm{CO}_{2}$ capture solvent. International Journal of Greenhouse Gas Control. 2018/08/01/ 2018;75:1-7.

11. Heldebrant DJ, Koech PK, Glezakou V-A, Rousseau R, Malhotra D, Cantu DC. Water-Lean Solvents for Post-Combustion $\mathrm{CO}_{2}$ Capture: Fundamentals, Uncertainties, Opportunities, and Outlook. Chemical Reviews. 2017/07/26 2017;117(14):9594-9624.

12. Tobiesen FA, Haugen G, Kim I, Kvamsdal H. Simulation and Energy Evaluation of Two Novel Solvents Developed in the EU Project HiPerCap. Energy Procedia. 2017/07/01/ 2017;114:1621-1629.

13. Rochelle GT. Amine Scrubbing for $\mathrm{CO}_{2}$ Capture. Science. Sep 2009;325(5948):1652-1654.

14. Sun J, Li Q, Chen G, Duan J, Liu G, Jin W. MOF-801 incorporated PEBA mixed-matrix composite membranes for $\mathrm{CO}_{2}$ capture. Separation and Purification Technology. 2019/06/15/ 2019;217:229-239.

15. Xie K, Fu Q, Qiao GG, Webley PA. Recent progress on fabrication methods of polymeric thin film gas separation membranes for $\mathrm{CO}_{2}$ capture. Journal of Membrane Science.2019/02/15/ 2019;572:38-60.

16. Merkel TC, Lin HQ, Wei XT, Baker R. Power plant post-combustion carbon dioxide capture: An opportunity for membranes. Journal of Membrane Science. Sep 2010;359(1-2):126-139.

17. Anantharaman R, Berstad D, Roussanaly S. Techno-economic Performance of a Hybrid Membrane Liquefaction Process for Post-combustion $\mathrm{CO}_{2}$ Capture. Energy Procedia.2014/01/01/ 2014;61:1244-1247.

18. Wilcox J, Haghpanah R, Rupp EC, He JJ, Lee K. Advancing Adsorption and Membrane Separation Processes for the Gigaton Carbon Capture Challenge. In: Prausnitz JM, Doherty MF, Segalman RA, eds.Annual Review of Chemical and Biomolecular Engineering, Vol 5.Vol 52014:479-+.

19. Haghpanah R, Majumder A, Nilam R, et al. Multiobjective Optimization of a Four-Step Adsorption Process for Postcombustion $\mathrm{CO}_{2}$ Capture Via Finite Volume Simulation. Industrial \& Engineering Chemistry Research. 2013/03/20 2013;52(11):4249-4265.

20. Yang J, Yu X, Yan J, Tu S-T, Dahlquist E. Effects of $\mathrm{SO}_{2}$ on $\mathrm{CO}_{2}$ capture using a hollow fiber membrane contactor. Applied Energy. 2013/12/01/ 2013;112:755-764.

21. Krzemień A, Wieckol-Ryk A, Smoliński A, Koteras A, Wiecław-Solny L. Assessing the risk of corrosion in amine-based $\mathrm{CO}_{2}$ capture process. Journal of Loss Prevention in the Process Industries. 2016/09/01/ 2016;43:189-197.

22. Joss L, Gazzani M, Mazzotti M. Rational design of temperature swing adsorption cycles for postcombustion $\mathrm{CO}_{2}$ capture. Chemical Engineering Science.2017/02/02/ 2017;158:381-394.

23. Bui M, Adjiman CS, Bardow A, et al. Carbon capture and storage (CCS): the way forward. Energy Environ. Sci.2018;11(5):1062-1176.

24. Zanco SE, Joss L, Hefti M, Gazzani M, Mazzotti M. Addressing the Criticalities for the Deployment of Adsorption-based $\mathrm{CO}_{2}$ Capture Processes. Energy Procedia.2017/07/01/ 2017;114:2497-2505. 
25. Liu L, Sanders ES, Kulkarni SS, Hasse DJ, Koros WJ. Sub-ambient temperature flue gas carbon dioxide capture via Matrimid (R) hollow fiber membranes. Journal of Membrane Science. Sep 2014;465:49-55.

26. Hasse D, Ma JF, Kulkarni S, et al. $\mathrm{CO}_{2}$ Capture by Cold Membrane Operation. In: Dixon T, Herzog $\mathrm{H}$, Twinning S, eds. 12th International Conference on Greenhouse Gas Control Technologies, Ghgt-12. Vol 63. Amsterdam: Elsevier Science Bv; 2014:186-193.

27. Hasse D, Kulkarni S, Sanders E, Corson E, Tranier JP. $\mathrm{CO}_{2}$ capture by sub-ambient membrane operation. In: Dixon T, Yamaji K, eds. Ghgt-11. Vol 37. Amsterdam: Elsevier Science Bv; 2013:993-1003.

28. Song $\mathrm{C}$, Liu Q, Ji N, et al. Reducing the energy consumption of membrane-cryogenic hybrid $\mathrm{CO}_{2}$ capture by process optimization. Energy. 2017/04/01/ 2017;124:29-39.

29. Lee S, Kim J-K. Process-integrated design of a sub-ambient membrane process for $\mathrm{CO}_{2}$ removal from natural gas power plants. Applied Energy. 2020/02/15/ 2020;260:114255.

30. Luyben WL. Estimating refrigeration costs at cryogenic temperatures. Computers $\&$ Chemical Engineering. 2017/08/04/ 2017;103:144-150.

31. DeWitt SJA, Rubiera Landa HO, Kawajiri Y, Realff M, Lively RP. Development of Phase-Change-Based Thermally Modulated Fiber Sorbents. Industrial \& Engineering Chemistry Research.2018/12/13 2018.

32. DeWitt SJA, Sinha A, Kalyanaraman J, Zhang F, Realff MJ, Lively RP. Critical Comparison of Structured Contactors for Adsorption-Based Gas Separations. Annual Review of Chemical and Biomolecular Engineering. 2018;9(1):129-152.

33. Lively RP, Bessho N, Bhandari DA, Kawajiri Y, Koros WJ. Thermally moderated hollow fiber sorbent modules in rapidly cycled pressure swing adsorption mode for hydrogen purification. Int. J. Hydrog. Energy. Oct 2012;37(20):15227-15240.

34. James RZ, Alexander; Keairns, Dale; Turner, Marc; Woods, Mark; Kuehn, Norma. Cost and Performance Baseline for Fossil Energy Plants Volume 1: Bituminous Coal and Natural Gas to Electricity : NETL;2019.

35. Boyce MP. 7 - Axial-Flow Compressors. In: Boyce MP, ed.Gas Turbine Engineering Handbook (Fourth Edition) . Oxford: Butterworth-Heinemann; 2012:303-355.

36. Park J, Rubiera Landa H, Kawajiri Y, Realff M, Lively R, Sholl D. How Well Do Approximate Models of Adsorption-Based $\mathrm{CO}_{2}$ Capture Processes Predict Results of Detailed Process Models? Industrial $E^{6}$ Engineering Chemistry Research.04/15 2020;59:7097-7108.

37. Dubbeldam D, Torres-Knoop A, Walton KS. On the inner workings of Monte Carlo codes. Molecular Simulation. 2013/12/01 2013;39(14-15):1253-1292.

38. Düren T, Bae Y-S, Snurr RQ. Using molecular simulation to characterise metal-organic frameworks for adsorption applications. Chemical Society Reviews. 2009;38(5):1237-1247.

39. Altintas C, Avci G, Daglar H, et al. Database for $\mathrm{CO}_{2}$ Separation Performances of MOFs Based on Computational Materials Screening. ACS Applied Materials \& Interfaces. 2018/05/23 2018;10(20):1725717268 .

40. Park J, Howe JD, Sholl DS. How Reproducible Are Isotherm Measurements in Metal-Organic Frameworks? Chemistry of Materials. 2017/12/26 2017;29(24):10487-10495.

41. Park J, Lively RP, Sholl DS. Establishing upper bounds on $\mathrm{CO}_{2}$ swing capacity in sub-ambient pressure swing adsorption via molecular simulation of metal-organic frameworks. Journal of Materials Chemistry A. 2017;5(24):12258-12265.

42. Tang D, Wu Y, Verploegh RJ, Sholl DS. Efficiently Exploring Adsorption Space to Identify Privileged Adsorbents for Chemical Separations of a Diverse Set of Molecules. ChemSusChem.2018;11(9):1567-1575. 
43. Agrawal M, Sava Gallis DF, Greathouse JA, Sholl DS. How Useful Are Common Simulants of Chemical Warfare Agents at Predicting Adsorption Behavior? The Journal of Physical Chemistry C.2018/11/15 2018;122(45):26061-26069.

44. Park J, Agrawal M, Sava Gallis DF, Harvey JA, Greathouse JA, Sholl DS. Impact of intrinsic framework flexibility for selective adsorption of sarin in non-aqueous solvents using metal-organic frameworks. Physical Chemistry Chemical Physics.2020;22(11):6441-6448.

45. Myers AL, Prausnitz JM. Thermodynamics of mixed-gas adsorption. AIChE Journal. 1965;11(1):121127.

46. Rubiera Landa HO, Flockerzi D, Seidel-Morgenstern A. A method for efficiently solving the IAST equations with an application to adsorber dynamics. AIChE Journal. 2013;59(4):1263-1277.

47. Dickey AN, Yazaydın AÖ, Willis RR, Snurr RQ. Screening $\mathrm{CO}_{2} / \mathrm{N}_{2}$ selectivity in metal-organic frameworks using Monte Carlo simulations and ideal adsorbed solution theory. The Canadian Journal of Chemical Engineering.2012;90(4):825-832.

48. Walton KS, Sholl DS. Predicting multicomponent adsorption: 50 years of the ideal adsorbed solution theory. AIChE Journal.2015;61(9):2757-2762.

49. Rubiera Landa HO, Lively RP, Kawajiri Y, Realff MJ. Theoretical Investigation of Vacuum pressureswing adsorptoin processes applying thermally modulated fiber composite adsorbents.

50. Müller J. SOCEMO: Surrogate Optimization of Computationally Expensive Multiobjective Problems. INFORMS Journal on Computing.2017;29(4):581-596.

51. MATLAB [computer program]. Version 9.6.0. (R2019a). Natick, MA: The MathWorks Inc.; 2019.

52. Rubiera Landa HO, Kawajiri Y, Realff MJ. Efficient Evaluation of Vacuum Pressure-Swing Cycle Performance using Surrogate-based, Multi-objective Optimization Algorithm. Paper presented at: Computer Aided Chemical Engineering: 30th European Symposium on Computer Aided Process Engineering (Part C) 2020 .

53. Castle WF. Fifty-Years' Development of Cryogenic Liquefaction Processes. In: Timmerhaus KD, Reed RP, eds. Cryogenic Engineering . New York, NY: Springer New York; 2007:146-160.

54. Agrawal R. Synthesis of Distillation Column Configurations for a Multicomponent Separation. Industrial E Engineering Chemistry Research. 1996/01/01 1996;35(4):1059-1071.

55. Castle WF. Air separation and liquefaction: recent developments and prospects for the beginning of the new millennium.International Journal of Refrigeration. 2002/01/01/ 2002;25(1):158-172.

56. Li Y, Wang X, Ding Y. An optimal design methodology for large-scale gas liquefaction. Applied Energy. 2012/11/01/ 2012;99:484-490.

57. Latimer RE. Distillation of Air. Chemical Engineering Progress. 1967;63(2):35-59.

58. Wetenhall $\mathrm{B}$, Aghajani $\mathrm{H}$, Chalmers $\mathrm{H}$, et al. Impact of $\mathrm{CO}_{2}$ impurity on $\mathrm{CO}_{2}$ compression, liquefaction and transportation. Energy Procedia. 2014/01/01/ 2014;63:2764-2778.

59. Yoo B-Y, Lee S-G, Rhee K-p, Na H-S, Park J-M. New CCS system integration with $\mathrm{CO}_{2}$ carrier and liquefaction process. Energy Procedia. 2011/01/01/ 2011;4:2308-2314.

60. Sujan AR, Koh D-Y, Zhu G, et al. High-Temperature Activation of Zeolite-Loaded Fiber Sorbents. Industrial $\&$ Engineering Chemistry Research. 2018/08/29 2018;57(34):11757-11766.

61. Fan $\mathrm{Y}$, Kalyanaraman $\mathrm{J}$, Labreche $\mathrm{Y}$, et al. $\mathrm{CO}_{2}$ Sorption Performance of Composite Polymer/Aminosilica Hollow Fiber Sorbents: An Experimental and Modeling Study. Industrial \& Engineering Chemistry Research. 2015/02/18 2015;54(6):1783-1795. 
62. Zhao T, Jeremias F, Boldog I, Nguyen B, Henninger SK, Janiak C. High-yield, fluoride-free and largescale synthesis of MIL-101(Cr). Dalton Transactions. 2015;44(38):16791-16801.

63. Ye S, Jiang X, Ruan L-W, et al. Post-combustion $\mathrm{CO}_{2}$ capture with the HKUST-1 and MIL-101(Cr) metal-organic frameworks: Adsorption, separation and regeneration investigations. Microporous and Mesoporous Materials. 2013/09/15/ 2013;179:191-197.

64. Chen G, Koros WJ, Jones CW. Hybrid Polymer/UiO-66(Zr) and Polymer/NaY Fiber Sorbents for Mercaptan Removal from Natural Gas.Acs Applied Materials 63 Interfaces. Apr 2016;8(15):9700-9709.

65. Liu Q, Ning L, Zheng S, Tao M, Shi Y, He Y. Adsorption of Carbon Dioxide by MIL-101(Cr): Regeneration Conditions and Influence of Flue Gas Contaminants. Scientific Reports. 2013/10/10 2013;3(1):2916.

66. Xu M, Chen S, Seo D-K, Deng S. Evaluation and optimization of VPSA processes with nanostructured zeolite $\mathrm{NaX}$ for post-combustion $\mathrm{CO}_{2}$ capture. Chemical Engineering Journal.2019/09/01/ 2019;371:693-705.

67. Akhtar F, Ogunwumi S, Bergström L. Thin zeolite laminates for rapid and energy-efficient carbon capture. Scientific Reports. 2017/09/08 2017;7(1):10988.

68. Haghpanah R, Nilam R, Rajendran A, Farooq S, Karimi IA. Cycle synthesis and optimization of a VSA process for postcombustion $\mathrm{CO}_{2}$ capture. AIChE Journal.2013;59(12):4735-4748. 